\title{
Summer monsoon intraseasonal oscillation over eastern Arabian Sea - as revealed by TRMM microwave imager products
}

\author{
S H RAHMAN* and B SiMON \\ Atmospheric Sciences Division, Meteorology and Oceanography Group, Space Applications Centre (ISRO), \\ Ahmedabad 380 015, Gujarat, India. \\ *e-mail: amar_bangla@yahoo.com
}

The time evolution of atmospheric parameters on intraseasonal time scale in the eastern Arabian Sea (EAS) is studied during the summer monsoon seasons of 1998-2003 using Tropical Rainfall Measuring Mission Microwave Imager (TMI) data. This is done using the spectral and wavelet analysis. Analysis shows that over EAS, total precipitable water vapour (TWV) and sea surface wind speed (SWS) have a periodicity of 8-15 days, 15-30 days and 30-60 days during the monsoon season. Significant power is seen in the 8-15-day time scale in TWV during onset and retreat of the summer monsoon. Analysis indicates that the timings of the intensification of 8-15, 15-30, and 30-60 days oscillations have a profound effect on the evolution of the daily rainfall over west coast of India. The positive and negative phases of these oscillations are directly related to the active and dry spells of rainfall along the west coast of India. The spectral analysis shows interannual variation of TWV and SWS. Heavy rainfall events generally occur over the west coast of India when positive phases of both 30-60 days and 15-30 days modes of TWV and SWS are simultaneously present.

\section{Introduction}

The southwest monsoon affects the lives of nearly one billion people by providing almost $80 \%$ of annual rainfall to the Indian subcontinent. The spatial and temporal distribution of monsoon rainfall over the region and its variability affect the agricultural output significantly. The interannual variability is reflected in the onset dates, the total seasonal rainfall and active and break phases within the monsoon season. It exhibits pronounced intraseasonal variability on time scales ranging from a few days to more than a month. The intraseasonal oscillation (ISO) of the monsoon is not periodic in nature. It has three broadbands of spectrum termed as synoptic scale variability of 6-9 days, quasi-biweekly mode of 10-20 days and intraseasonal mode of 30-60 days (Krishnamurti and Bhalme 1976; Krishnamurti and Ardunay 1980; Yasunari 1980).

The Indian summer monsoon has a vigorous intraseasonal 30-60 days of low frequency oscillation in the form of active and weak or break spells of the monsoon rainfall within the summer monsoon season (Ramamurthy 1969). These active and break spells of the monsoon are associated with fluctuations of the Tropical Convergence Zone (TCZ) (Sikka and Gadgil 1980; Yasunari 1980). Recently Francis and Gadgil (2002) have shown that $62 \%$ of the intense rainfall events over the west coast of India are associated with the tropical convergence zone (TCZ). The number of monsoon breaks and their timing had a profound impact on agricultural output of the Indian subcontinent (Webster et al 1998). The presence of a large number of high frequency oscillations during the

Keywords. Intraseasonal oscillation; wavelet analysis; Indian summer monsoon. 


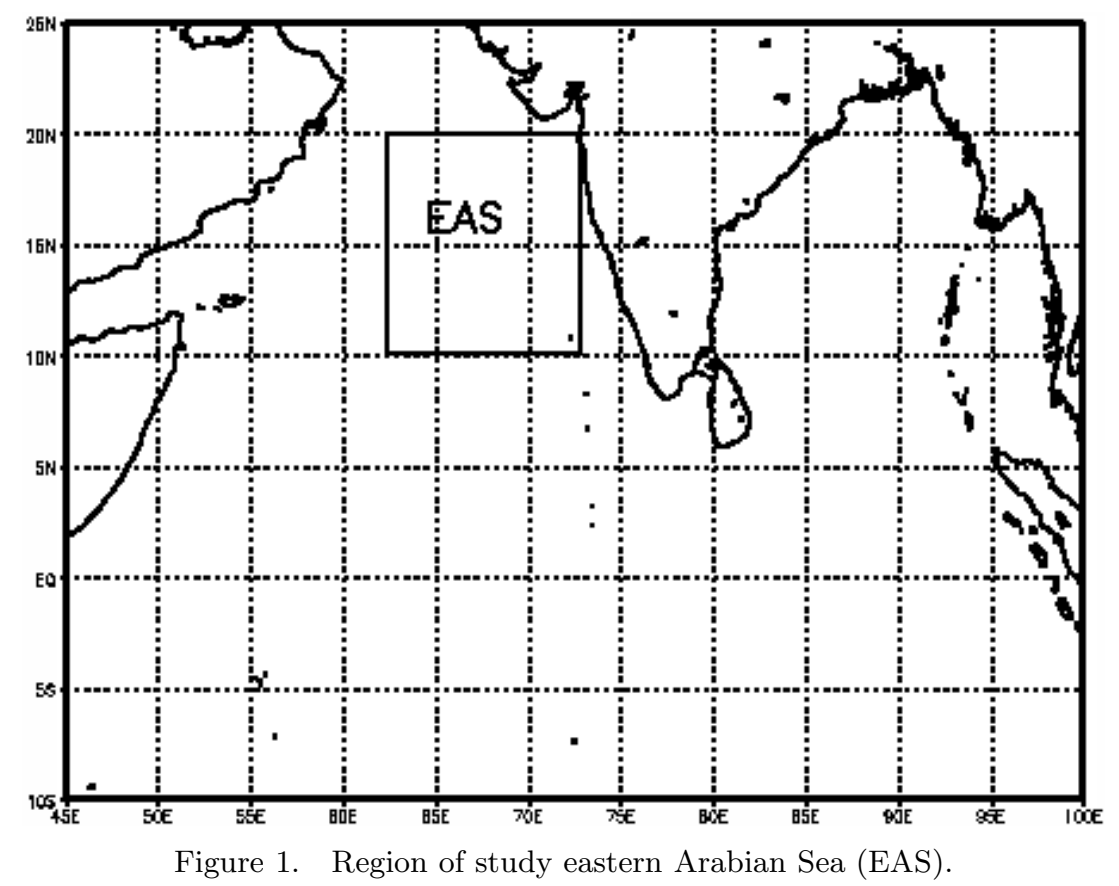

monsoon season could account for a stronger than normal seasonal mean monsoon (Goswami and Ajaya Mohan 2001). The role of ISOs in modulating synoptic and interannual variations of surface winds has been studied by Goswami et al (1998). Their finding reveals the dominant modes of 3060 days and 10-20 days periodicity. Singh et al (1992) suggest that the intensity of the intraseasonal oscillation is not related to the overall performance of the all India monsoon rainfall. Yasunari (1980) observed that during the drought years the periodicity of the intraseasonal oscillation increases to 60 days as compared to 40 days in the normal monsoon years. Intraseasonal oscillation was also studied using in situ observations (Krishnamurti et al 1988) and through numerical simulation (Ferranti et al 1997). Sengupta et al (2001) studied ISO over Indian Ocean and western Pacific during the summer monsoons of 19982000 using TMI data. Their finding reveals that the cause of ISO in sea surface temperature (SST) in Bay of Bengal (BoB) is mainly due to the net heat flux variability.

However in the above studies, no detailed mention is made about the timing of intensification of the ISO and its effect on monsoon rainfall. In this paper an attempt has been made to explore this relationship over EAS using long-term microwave satellite data from TMI, which has the advantage of providing data during cloudy conditions. In the present study we have used wavelet analysis to study the characteristics of the intraseasonal oscillations. This will bring out the features of the active and break cycles of the monsoon rainfall and its association with the ISOs. The data and methodology are discussed in section 2, whereas results and conclusions are discussed in section 3 and section 4 respectively.

\section{Data and methodology}

In this study, we have used daily TWV and SWS from TMI during the summer monsoon period (June-September) of 1998-2003. The data used is daily gridded version 3a data available online at http://www.ssmi.com/. The ascending and descending tracks data are linearly interpolated in time and then averaged to produce the dataset. We have also used the daily rainfall data obtained from Indian Daily Weather Report (IDWR) provided by the India Meteorological Department (IMD).

The wavelet transform is a useful alternative to the fast Fourier Transform for spectral analysis. It has the advantage of seeing the non-stationary time series in both the time and frequency domain simultaneously. This analysis tool is well suited to study the multi-scale, non-stationary process. By decomposing a time series into time-frequency space, one is able to determine both the dominant modes of variability and their variation in time. Wavelet transform uses generalized wave functions called wavelets that can be stretched and translated both in time and frequency. The continuous wavelet transform is defined as follows (Weng and Lau 1994):

$$
W(b, a)=\left(\frac{1}{\sqrt{ } a}\right) \int \Psi^{*}\left(\frac{t-b}{a}\right) s(t) d t,
$$


(a)
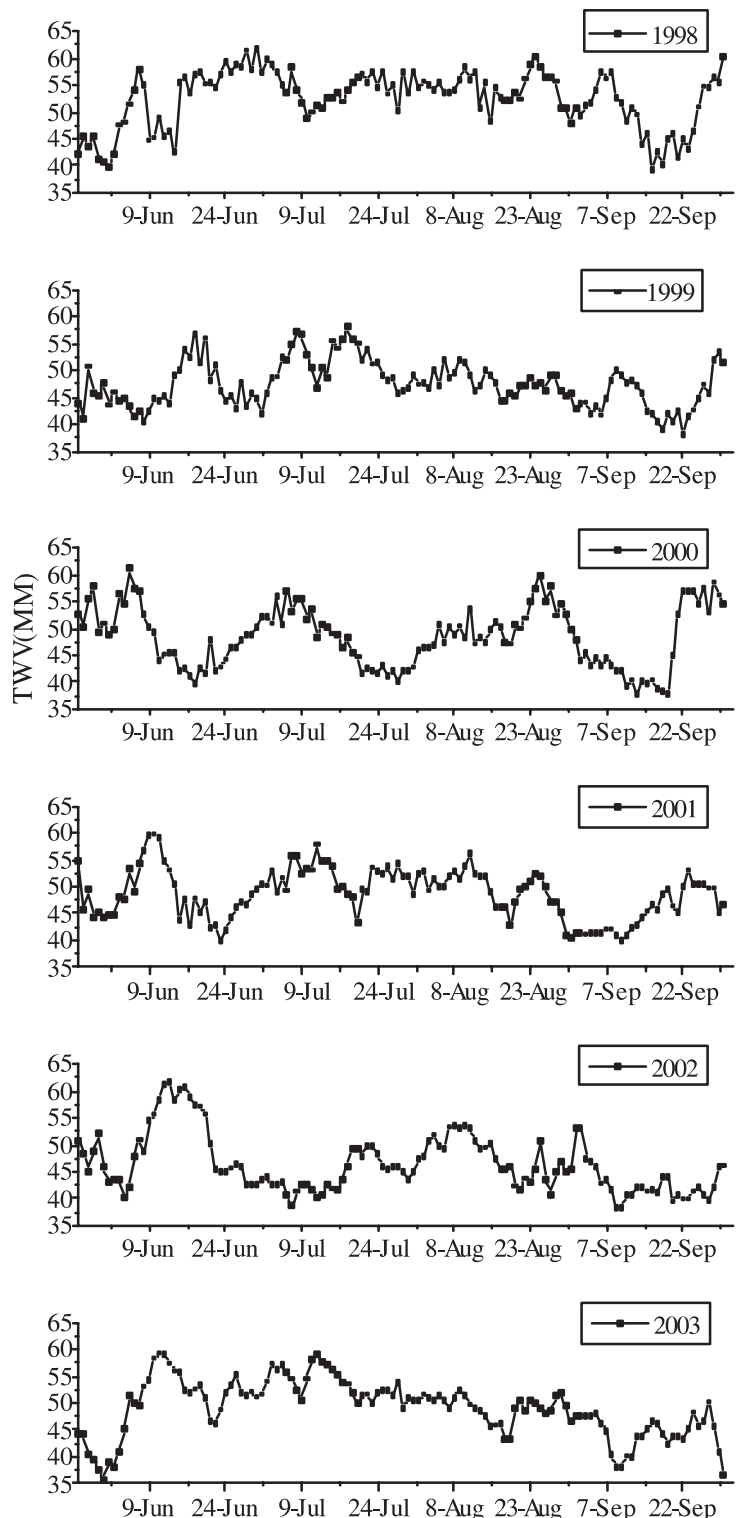

(b)
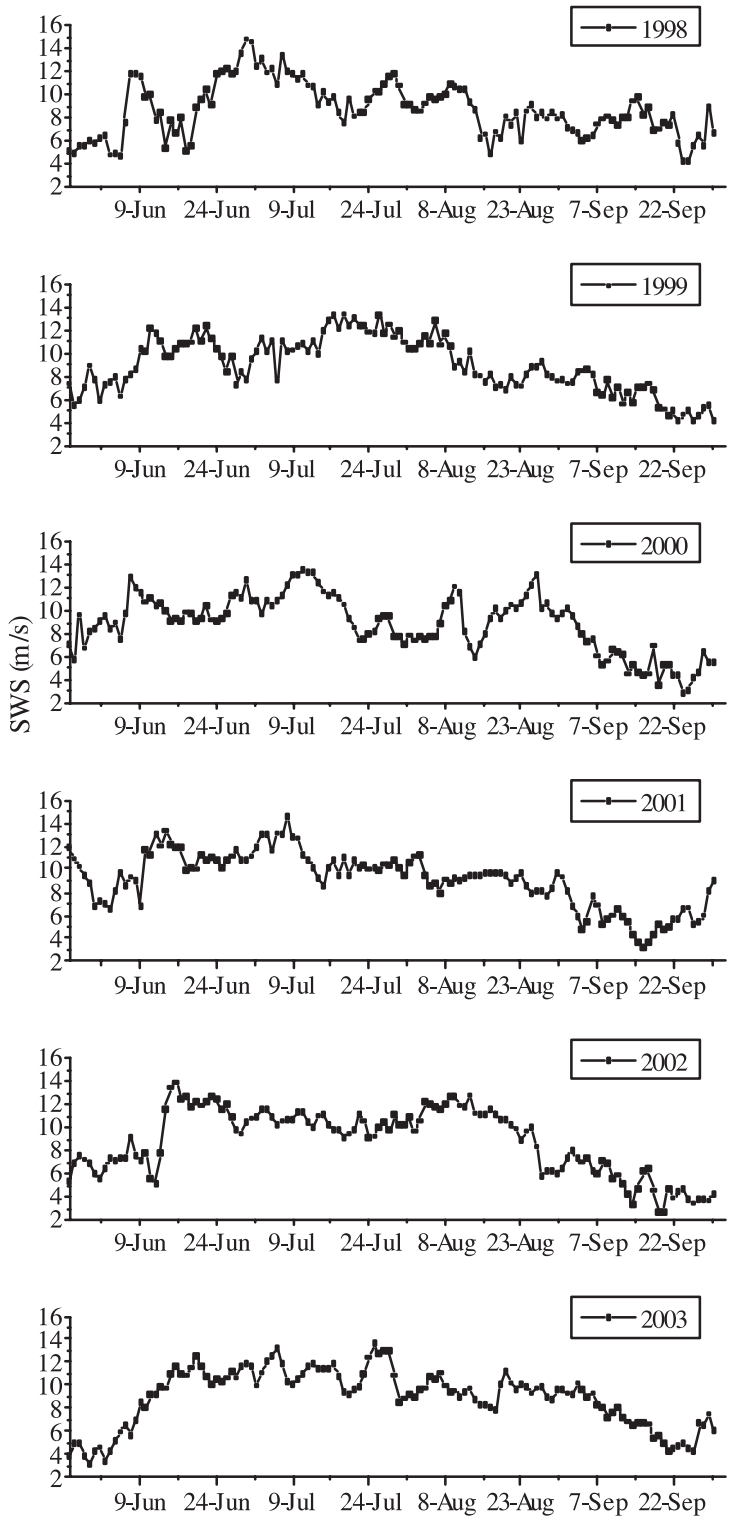

Figure 2. Daily mean (a) TWV (mm) and (b) SWS (m/s) for 1998-2003.

where $\Psi^{*}$ is the complex conjugate of $\Psi, b$ is the position (translation) parameter, and $a(>0)$ is scale (dilation) parameter.

The analyzing wavelet $\Psi(t)$ for Morlet wavelet transform is $\Psi(t)=\mathrm{e}^{i k_{\Psi} t} \mathrm{e}^{-|t \cdot t| / 2}$, which is plane wave modulated by a Gaussian, is narrow in frequency space, giving it a finer spectral resolution than the Mexican hat wavelet. In general there is a trade-off between spatial and spectral resolution inherent in the choice of wavelet (Torrence and Compo 1998).

The Morlet wavelet transform is applied to the area averaged daily TWV and SWS over the EAS $\left(63^{\circ}-73^{\circ} \mathrm{E}\right.$ and $10^{\circ}-20^{\circ} \mathrm{N}$; figure 1$)$ for the monsoon seasons of 1998-2003. The length of the data set is kept as 128 days (26 May-30 September).
A few data gaps in the time series are filled by linear interpolation. In the wavelet plots the abscissa is periodicity in days and the ordinate is time in days. The value of $k_{\psi}$ is taken as 5.4. Here the real parts of the complex Morlet wavelet transform have been shown as both intensity and phase diagram. The wavelet power spectra have been also analysed using Torrence and Compo (1998) algorithm with white and red noise background spectrum.

\section{Result and discussions}

\subsection{Time series analysis}

In order to study the evolution of TWV and SWS during onset and the following monsoon season, 
(a)

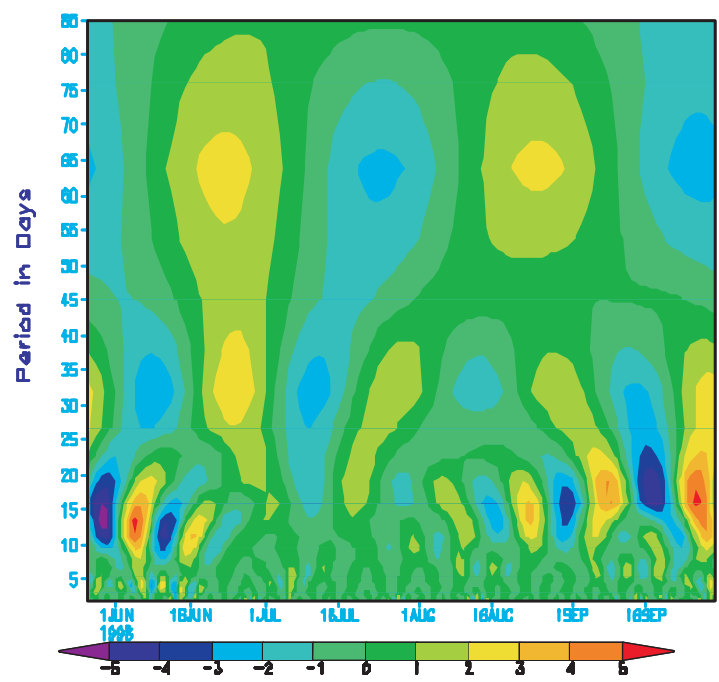

(b)

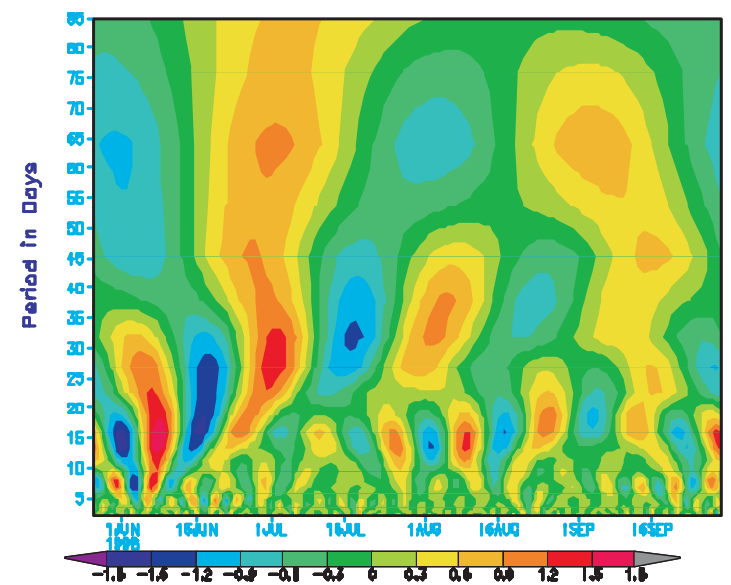

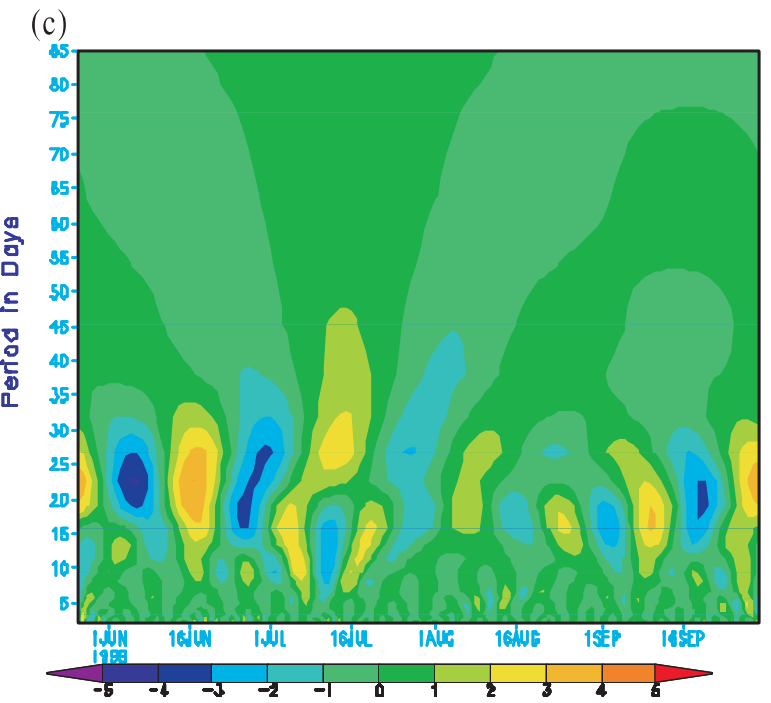

SWS

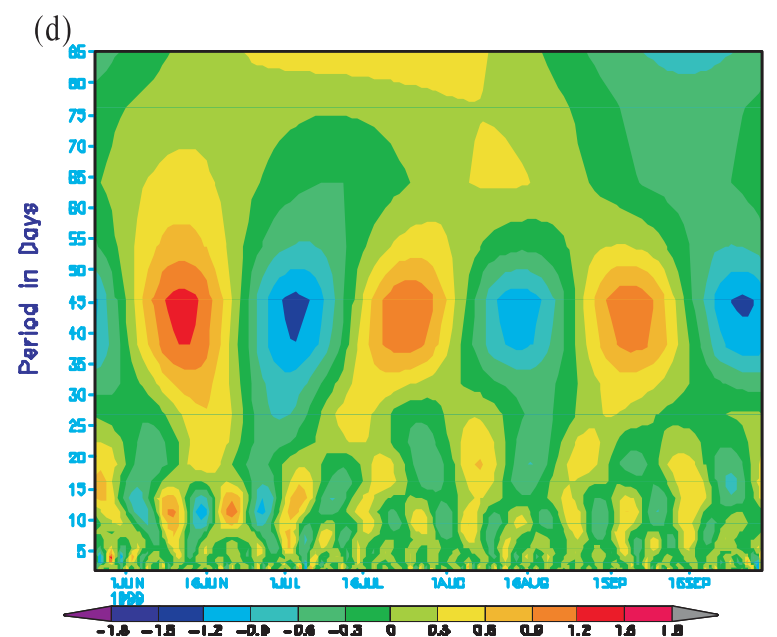

Figure 3. Real Morlet Wavelet coefficient in eastern Arabian Sea (a) TWV, (b) SWS for 1998, (c) and (d) for 1999.

these parameters were averaged over EAS (19982003 ) and shown in figure 2 . The water vapour content in EAS varies in the range of $35-65 \mathrm{~mm}$ during the summer monsoon period (figure 2a). The time series of wind field over EAS varies in the range about $6-14 \mathrm{~m} / \mathrm{s}$ (figure $2 \mathrm{~b}$ ). Significant changes are seen in TWV and SWS during the onset period. TWV content increases sharply from $\sim 45 \mathrm{~mm}$ to $55 \mathrm{~mm}(25 \%)$ during onset time and it remains relatively high $(\sim 55-60 \mathrm{~mm})$ during the active period. SWS also shows a sharp increase from $\sim 6 \mathrm{~m} / \mathrm{s}$ to $12 \mathrm{~m} / \mathrm{s}$ (100\% increase).

The moisture availability over EAS increases the chance of convection in addition to the BoB which strengthens the monsoon flow and thereby the moisture convergence. Out of the six years studied, 2002 was a drought year whereas other years were normal monsoon years. The time series of TWV over EAS during 2002 shows that TWV is less than $50 \mathrm{~mm}$ with one peak in the middle of
June, and remains less than $50 \mathrm{~mm}$ from the second half of June till the end of September. This indicates the requirement of moisture over the monsoon domain for a good monsoon. Time series of TWV in 1998 and 2003 also shows the presence of high TWV (>50 mm) throughout the monsoon period which is reflected in the All India Monsoon Rainfall (AIMRF). In 1998 and 2003, AIMRF were $105 \%$ and $102 \%$ of its long-term mean.

\subsection{Wavelet analysis}

The time series of TWV and SWS show fluctuating nature over the EAS region. Hence the wavelet analysis was applied to decompose the various modes of variation in the above time series after removing the seasonal mean. Recently Sajith et al (2003) have identified the dominant modes of ISO over BoB and Arabian Sea (AS). Over the AS periods less than 30 days are significant whereas 
(a)

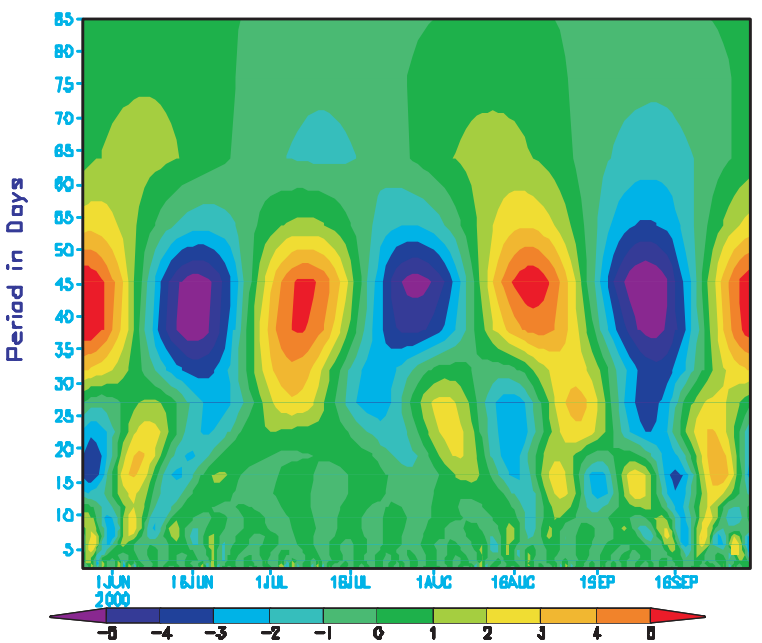

(b)

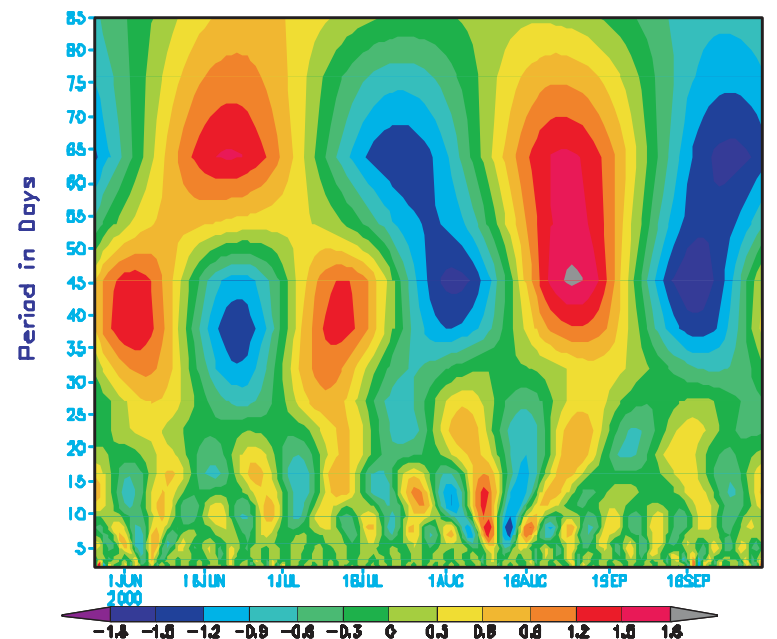

(c)

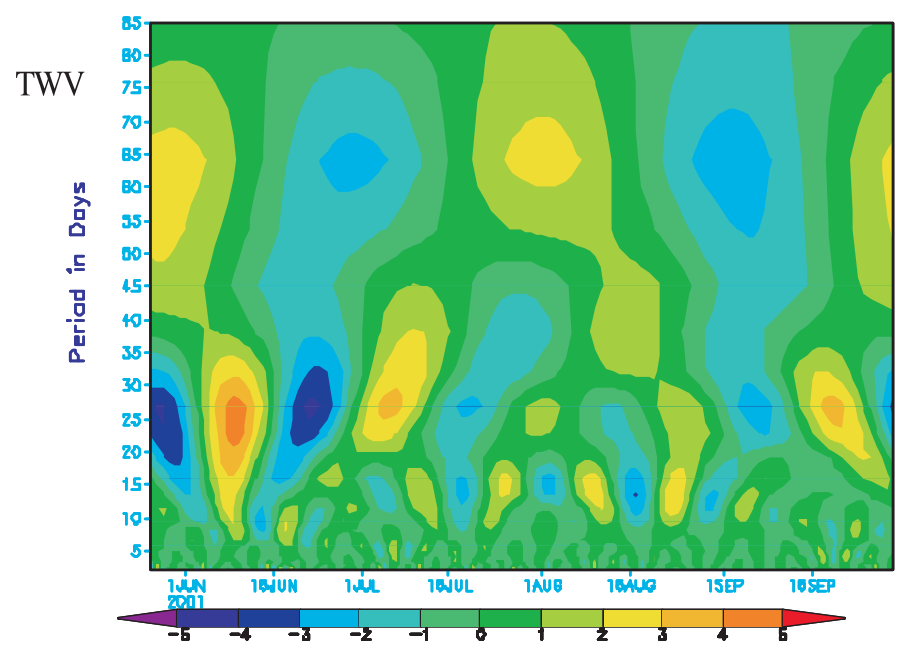

SWS

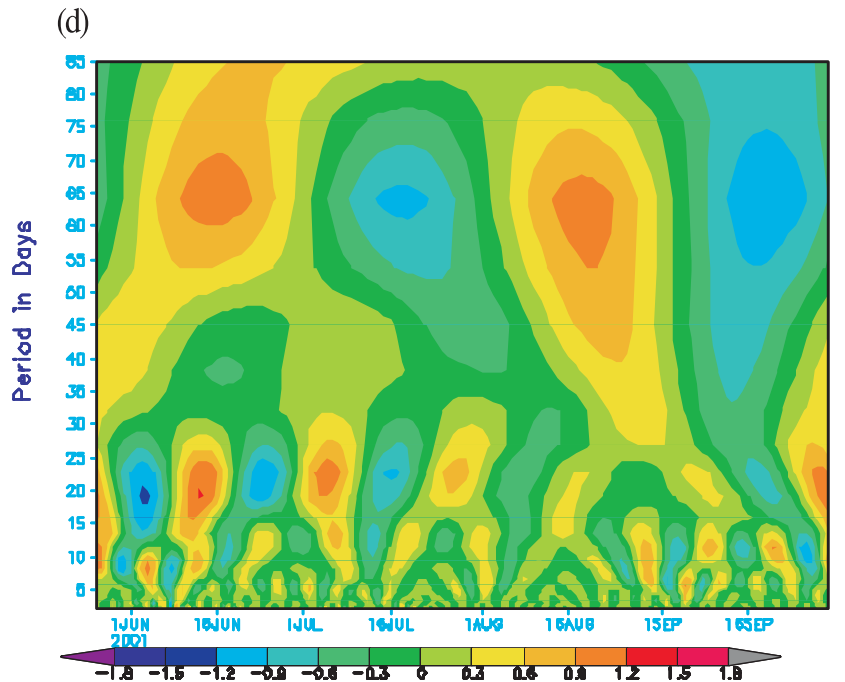

Figure 4. Real Morlet Wavelet coefficient in eastern Arabian Sea (a) TWV, (b) SWS for 2000, (c) and (d) for 2001.

over BoB 45.2 and 9.5-day periods are significant. Joseph et al (2004) using 95 years of station rainfall data over Kerala (gateway of Indian summer monsoon) have identified the short and long group of waves having periodicities in 23, 27 and 32 days in short and a single period of 64 days in the long group of ISOs.

In 1998, 32 and 64-day oscillations are seen throughout the monsoon season in TWV (figure 3a) whereas 8-16 days oscillation was strong during the onset and retreat period (indicative of transitions) but virtually absent during the peak monsoon months of July. There is a modulation of 8-16-day mode to high periodicity (i.e., low frequency) wave towards the end of the monsoon season. The exact cause of this kind of modulation is unknown but, Weng and Lau (1994) had suggested that the synoptic variability in the tropics is due to the combination of latent heat induced circulation instability and instability in the zonal flow in the tropical atmosphere. The intraseasonal oscillations have been considered essentially as selfexcited internal modes and are not caused by external forcing. The negative phase of both 64 days and 32 days oscillation during the first half of July brings the break phase of monsoon during 15-26 July.

Similarly 64 and 10-20 days period oscillations in SWS are prominently seen during the monsoon season (figure $3 \mathrm{~b}$ ). The presence of high frequency modes (periods $4-8$ days and $8-16$ days) were prominent during the last week of May and the first week of June. This may be due to the presence of very severe cyclonic storms (VSCS) and deep depression (DD) present during that time. This indicates that high-frequency ISO may be caused by synoptic scale systems, in conformity with the results of Weng and Lau (1994).

The positive phase of the low frequency 30-60 days oscillations of TWV and SWS is prominent 
(a)

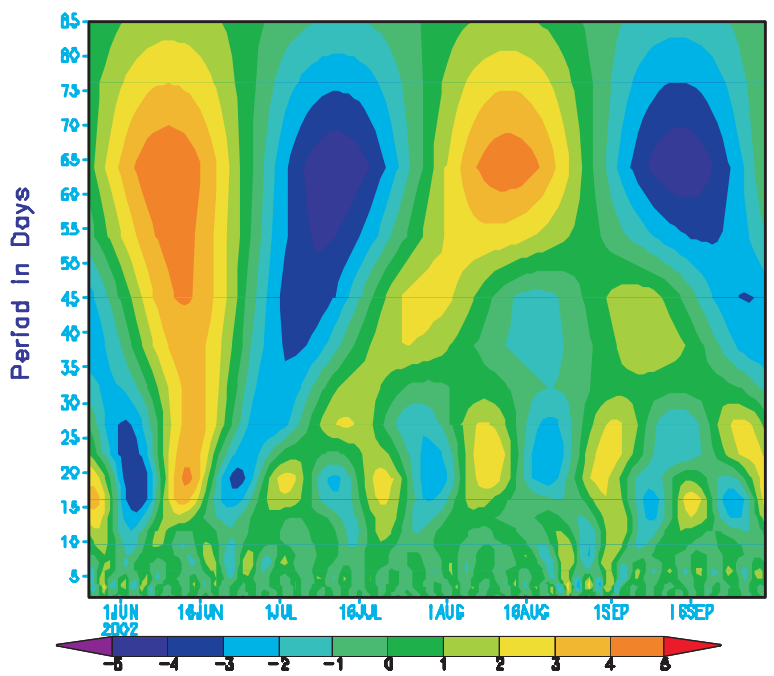

(b)

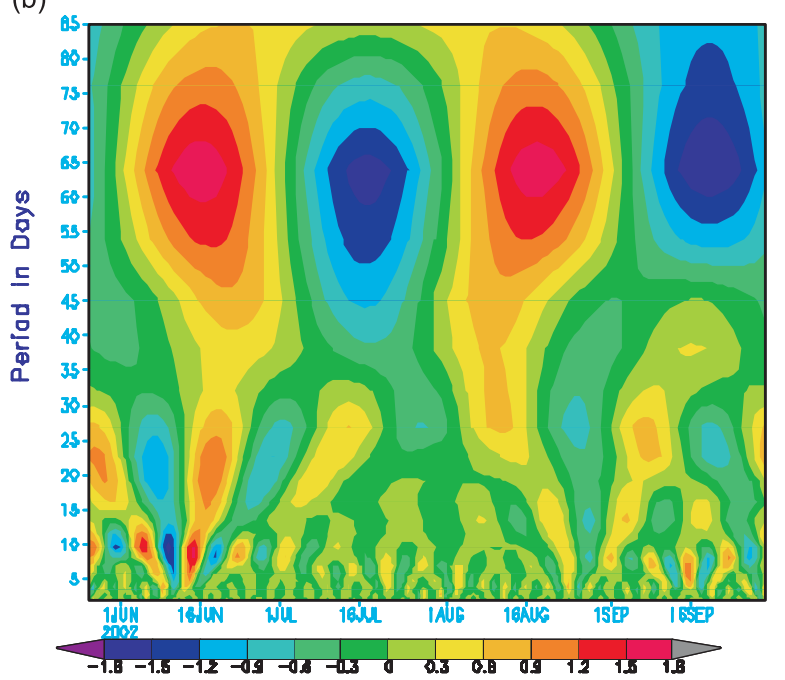

(c) TWV

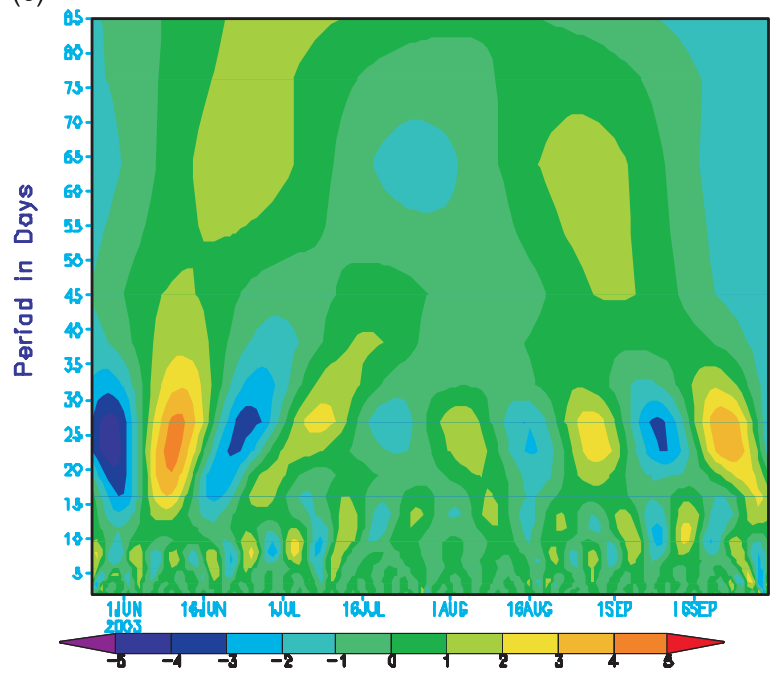

SWS

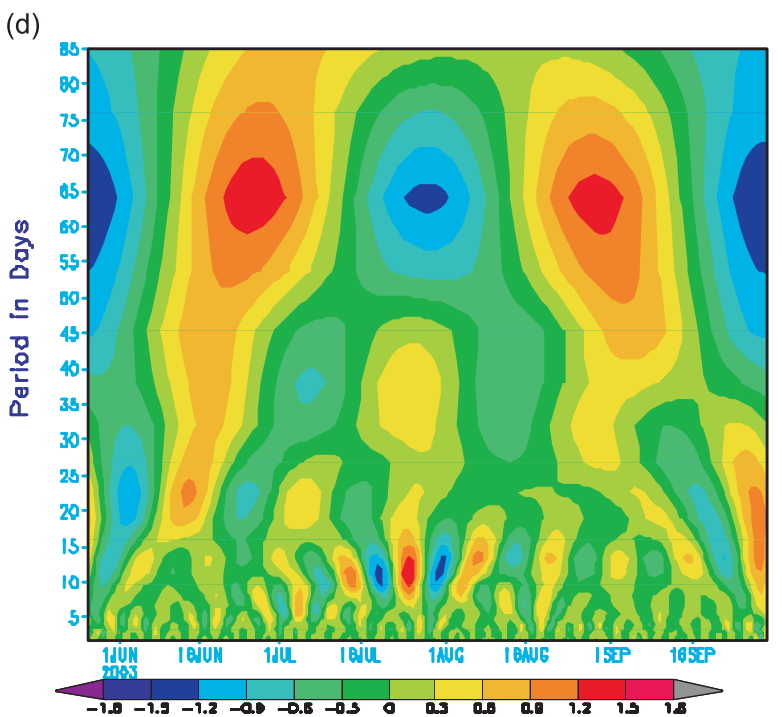

Figure 5. Real Morlet Wavelet coefficient in eastern Arabian Sea (a) TWV, (b) SWS for 2002, (c) and (d) for 2003.

between 10 June and 10 July and again between 10 August and 6 September. However in the TWV, the low frequency 30-60-day oscillation is lagging with those of the SWS by about 8-10 days. Rainfall activity is subdued over the west coast of India during the negative phase of the different modes in TWV and SWS (figure $7 \mathrm{~b}$ ). The west coast rainfall is taken as the average rainfall over the 5 stations (Mumbai, Mangalore, Mahabaleswar, Panjim and Trivandrum). In general the west coast rainfall is affected by the low frequency 30-60 days mode, associated with TCZ (Francis and Gadgil 2002) and 15-30 days period oscillations in TWV and SWS (Simon et al 2003). The simultaneous presence of high frequency mode along with the low frequency mode leads to a very active phase in monsoon rainfall, which supports the findings of Kripalani et al 2004. The major breaks during
15-26 July and 21-31 August are due to the negative phases in 15-30 and 30-60 days modes in TWV and SWS.

In 1999, the low frequency oscillation of 64 days in TWV is absent but the other (high frequency) modes are present during monsoon season (figure 3c). In SWS a very prominent 30-60-day period oscillation is seen throughout the monsoon season having amplitude of $0.9-1.5 \mathrm{~m} / \mathrm{s}$. Apart from these, 10-20-day oscillation was also present throughout the monsoon season (figure 3d). In 2000, the first positive phase of $30-60$ days mode oscillation in TWV was started around the last week of May, and gave considerable high rainfall over the west coast of India up to the middle of June (figure 8b). The next two prolonged active periods came corresponding to the two positive phases around the first week of July and third week of August. This 

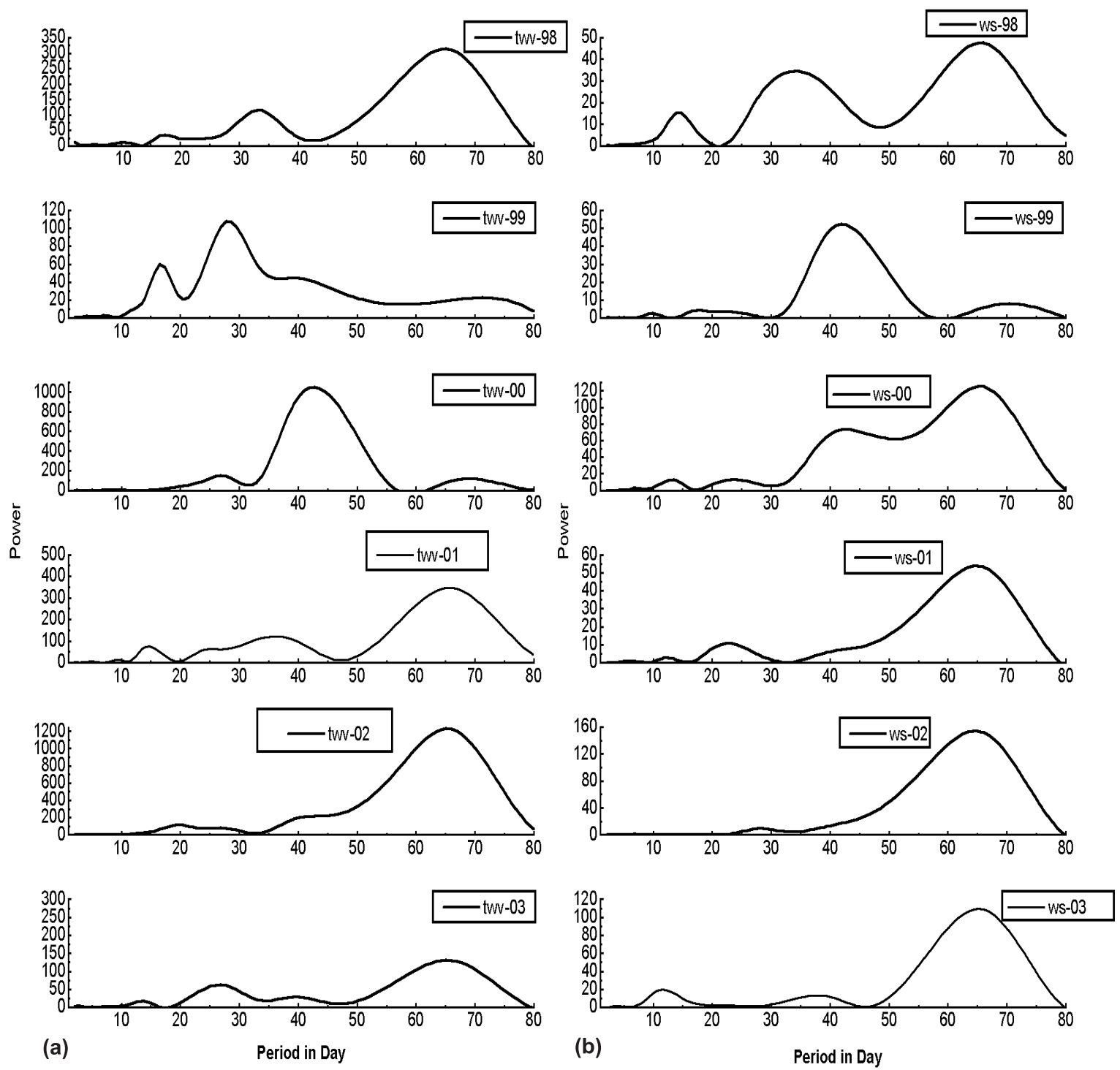

Figure 6. Fourier power spectra of (a) TWV and (b) SWS for 1998-2003.

results in a lull condition in rainfall during the end of September. Low period 10-20-day oscillation is almost absent during the whole monsoon season except towards the end. SWS modes of 3050-day period oscillation followed the same pattern as that of TWV with a 3-8 days phase difference (figure 4b). In 2001, 64-day and broadband of 1030 days modes of oscillation in TWV (figure 6c) and SWS (figure 6d) are present almost throughout the monsoon season but their amplitudes were weaker as compared to 1999 and 2000.

Kripalani et al 2004, using all India rainfall data of 2002 and 2003 have shown that 10-20 days mode oscillations dominated during monsoon of 2003 and 30-60 days mode of oscillations had dominated in 2002 monsoon. The analysis of TWV also shows clear dominance of low frequency oscillation in 2002 (figure 5a). The amplitude of $50-70$ days periodicity wave is maximum in 2002 when compared to all other years. Fourier spectrum analysis also confirms this (figure 6a). High frequency oscillation was almost absent during the entire monsoon season. In SWS high amplitude 50-70 days period oscillation was also seen throughout the monsoon season of 2002. Low periodicity $4-16$ days oscillation is only present during the onset period, thereafter it reappears at the end of the monsoon season (figure 5b). Absence of low periodicity waves in TWV and SWS during the monsoon season may be one of the reasons for the occurrence of drought in 2002. This is in corroboration with the findings of Goswami and Ajaya Mohan (2001). In 2003, low period oscillation was dominant in TWV during the onset and retreat phase of monsoon (figure 5c) whereas it was dominant in SWS during peak monsoon period (figure $5 \mathrm{~d}$ ). This suggests 

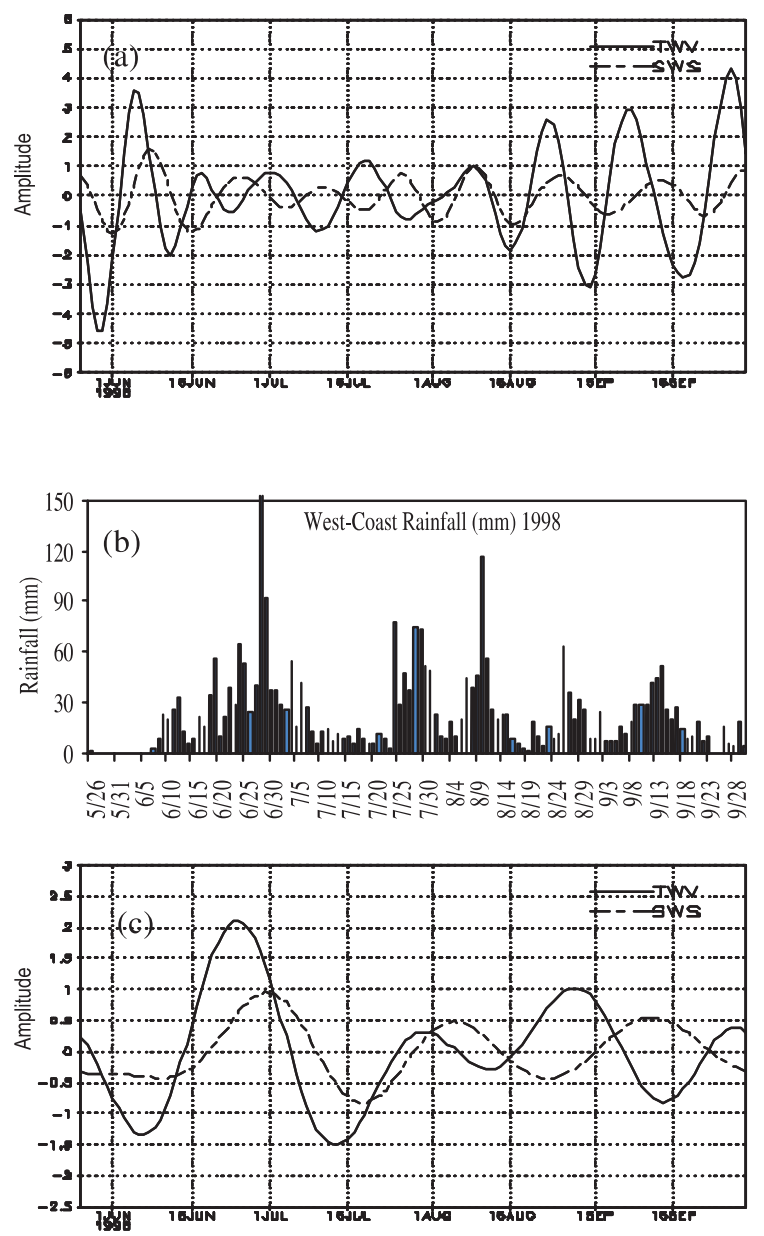

Figure 7. Wavelet spectra of 10-20 days mode (a) 1998, spectra of 30-60 days mode, (c) 1998 and (f) 1999.
10-20 day
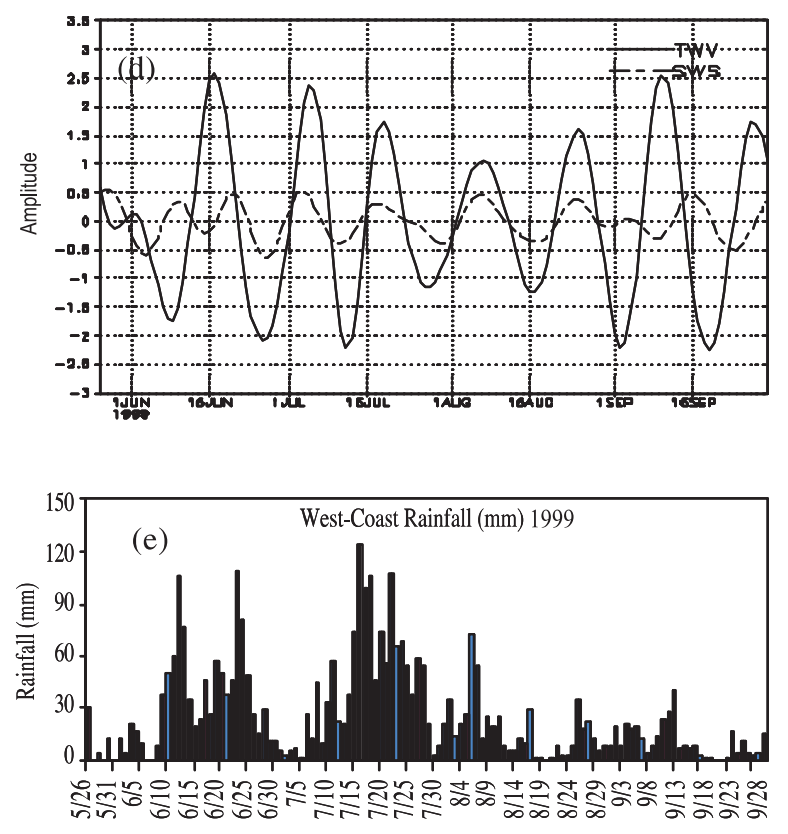

30-60 day

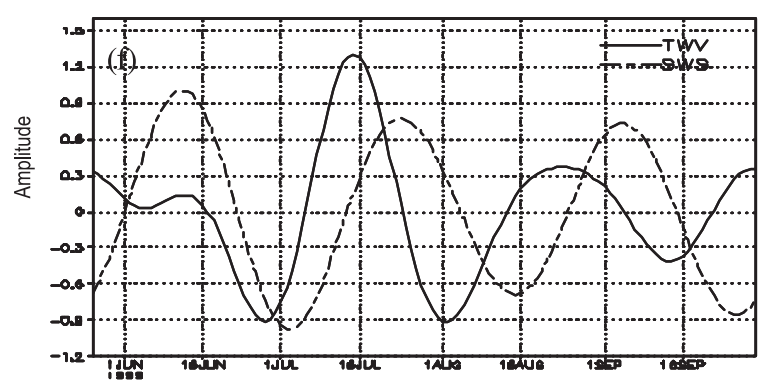

, (d) 1999, west-coast station rainfall, (b) 1998, (e) 1999, wavelet

the importance of low periodicity ISO during peak monsoon period.

\subsection{Spectral analysis}

The Fourier power spectral analysis of TWV for 1998-2003 is shown in figure 6a. It clearly shows the inter-annual variability of ISO. It reveals that for a normal or good monsoon year the presence of high frequency modes are prominent apart from low frequency modes of 30-60 days. SWS (figure $6 \mathrm{~b}$ ) also shows the inter-annual variability of ISO. Out of the 6 years studied, 2002 was a drought year, which shows a unique period of 64 days in TWV and SWS having high powers.

In order to see the inter-annual variability of low and high periodicity waves in two broadband spectrums, (a) 30-60 day and (b) 10-20 day, we have filtered the wavelet coefficients of TWV and SWS in these two bands and then studied. In 1998, the amplitude of 10-20-day SWS band was more or less constant $\sim \pm 1 \mathrm{~m} / \mathrm{s}$ throughout the monsoon season, however in 1999 its amplitude was $\sim \pm 0.5 \mathrm{~m} / \mathrm{s}$. The amplitude of TWV mode was large during onset and retreat period in almost all the years studied (figure 7a, d). In the 30-60-day period oscillations band the maximum amplitude of TWV reached up to $2 \mathrm{~mm}$ during the last week of June whereas in 1999 its maximum amplitude reached around the middle of July $(1.2 \mathrm{~mm})$ (figure 7c, f). In SWS although the maximum amplitude was $\sim \pm 1 \mathrm{~m} / \mathrm{s}$ for both the years it was more or less sinusoidal in 1999. In 1998, large negative phase of TWV and SWS in both 30-60-day and 10-20-day periodicity oscillations band during the second week of July corresponds to the break phase of monsoon during 15-25 July (figure 7b). In 1999, prolonged active spells in west-coast rainfall during the middle of June and middle of July correspond to positive phases of TWV and SWS (figure 7e). Hence the west-coast rainfall depends on the timing of the positive and negative phases of TWV and SWS, i.e., the timing of the intensification of ISO. This supports the finding of Francis and Gadgil (2002) that the west-coast rainfall are modulated by the synoptic scale Tropical Convergence Zone (TCZ). 

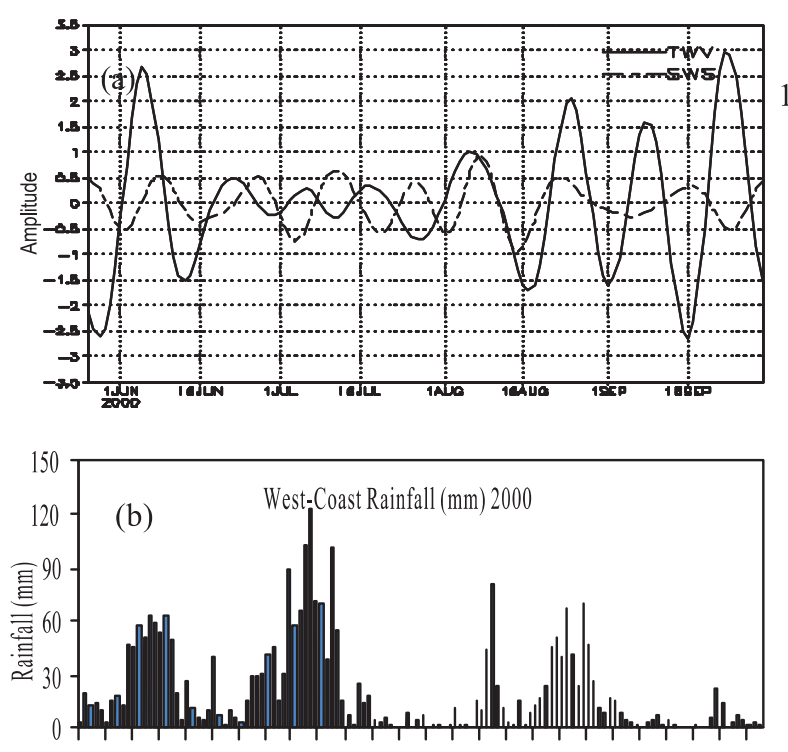

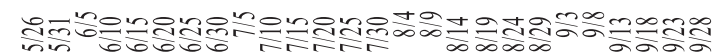

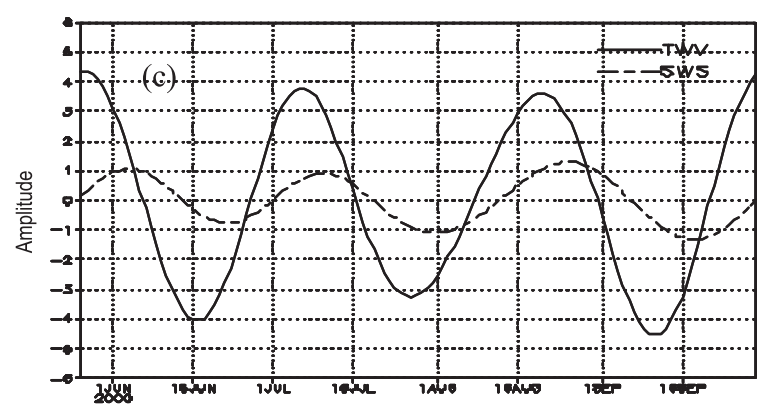

Figure 8. Wavelet spectra of 10-20 days mode (a) 2000, spectra of 30-60 days mode, (c) 2000 and (f) 2001.

Figure 8(a, d) shows the quasi-biweekly 10-20 days mode in TWV and SWS for 2000 and 2001. It can be seen from this figure that high amplitude oscillation persists during the onset and retreat period and it is modulated during the peak monsoon period. However in the case of SWS, the amplitude remains almost constant throughout the monsoon season.

Figure 8(c, f) shows the 30-60-day period band in TWV and SWS for 2000 and 2001. Three clear-cut epochs in west-coast rainfall are seen corresponding to the positive phases of TWV modes (figure 8b, c). The phase difference between TWV and SWS is about $8-10$ days. The high active periods correspond to positive phases of both 30-60 and 10-20 days oscillation.

Figure 9(a) shows the 10-20 days band oscillation in TWV and SWS for 2002. Unlike other years, modulation of TWV during peak monsoon month is absent in 2002. The most interesting feature in SWS is the near complete absence of this mode during peak monsoon months of July and August as compared to the other years of study.
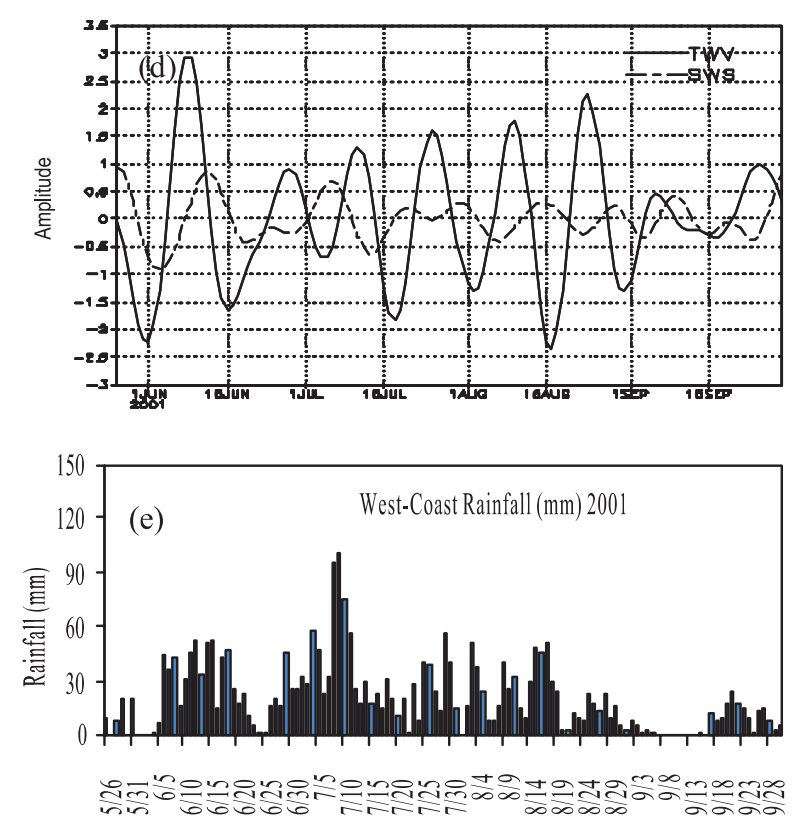

30-60 day

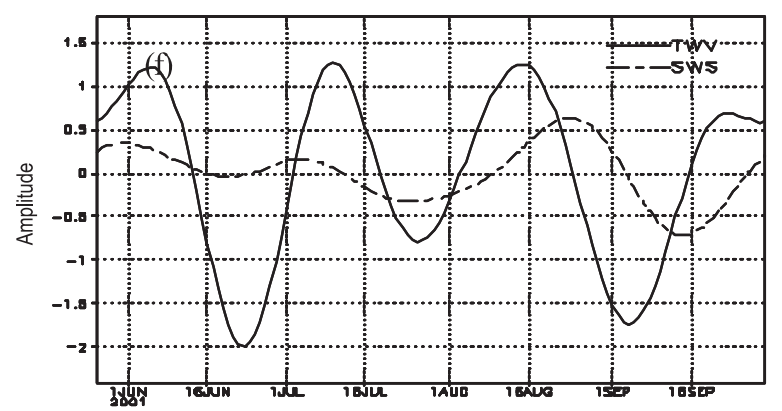

(d) 2001, west-coast station rainfall, (b) 2000, (e) 2001, wavelet Figure 9c shows the 30-60 days band in TWV and SWS for 2002. The high amplitude $(\sim 4 \mathrm{~mm})$ in TWV is seen during onset period and modulated to lower amplitude at the end of the monsoon season. It is still unanswered whether atmospheric oscillations on the time scale of $30-50$ days are entirely forced by internal atmospheric instability or whether they are related to coupling between ocean and atmosphere. The cause of modulation is still unknown. In SWS also the periodicity was in lower side of 30-60-day mode with amplitude about $\pm 1 \mathrm{~m} / \mathrm{s}$ (figure 9c). This fact strengthens the finding of Goswami et al (1998). They found that the composite structure of the 30-60-day mode is strikingly similar to the dominant mode of inter-annual variability of the seasonal mean winds indicating a strong link between the ISO and the seasonal mean. In 2003, the maximum amplitude of TWV in 30-60-day periodicity wave reached $1.5 \mathrm{~mm}$ during onset period, thereafter it is confined to more or less $\pm 0.6 \mathrm{~mm}$. SWS also followed the same pattern except that the order of magnitude was different (figure 9f). Hence, the 

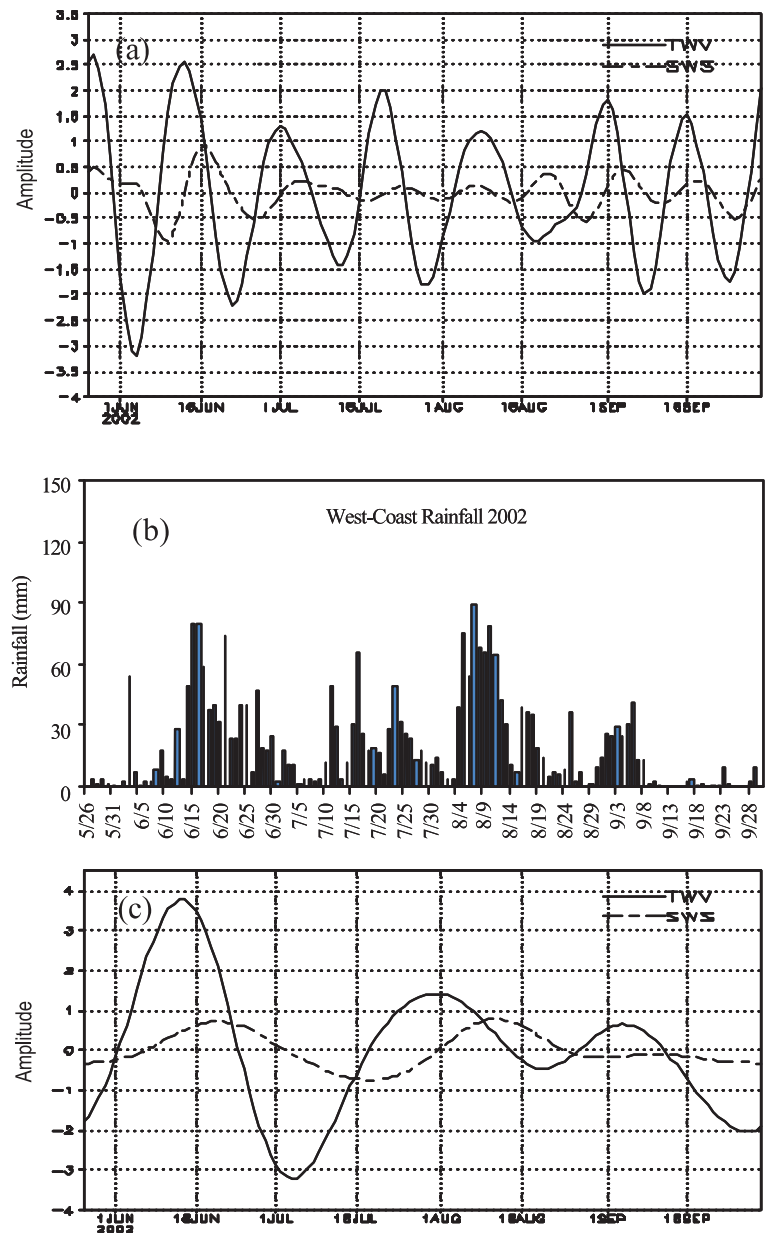

Figure 9. Wavelet spectra of 10-20 days mode (a) 2002, spectra of 30-60 days mode, (c) 2002 and (f) 2003.
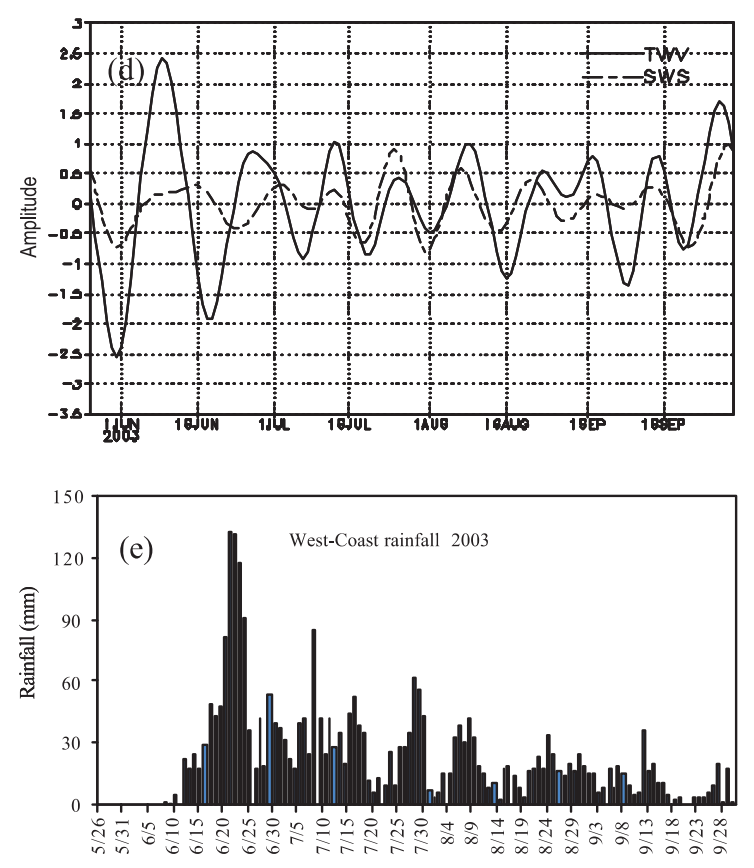

30-60 day

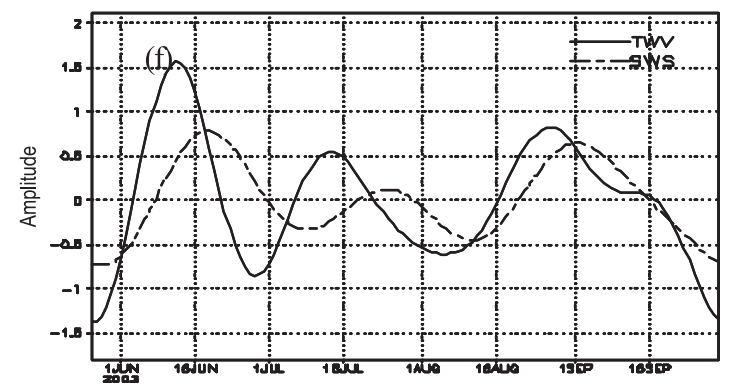

(d) 2003, west-coast station rainfall, (b) 2002, (e) 2003, wavelet

presence of high frequency modes in TWV and SWS throughout the monsoon season brings more number of rainy days along the west coast of India throughout the monsoon season (figure 9e).

In order to see the confidence level of different modes present, we did power spectrum analysis with red and white noise as background spectrum (Torrence and Compo 1998). The analysis shows that the 4-8 days and 8-16 days modes in TWV and SWS are significant at $90 \%$ confidence level when used red noise back ground spectrum (figure 10). The thick contour line signifies the $90 \%$ confidence levels and the cross hatch portion show the cone of influence. The cone of influence in the power spectrum is the part where edge effect comes in to the picture. As we are not using cyclic data sets, in order to reduce edge effect we have padded with zeroes. Padding with zeroes will reduce the power near the edge. As we have used 128 days time series for wavelet analysis, it is obvious that the periods longer than 30 days are almost always significant which we have also checked by using white noise back ground spectrum. One of the interesting features is that the presence of high frequency oscillations (8-16 days) in TWV during onset phase which is highly significant at $95 \%$ confidence level.

\section{Conclusions}

Time series analysis of TWV and SWS from TMI for 1998-2003 over EAS shows that almost 25\% increase of TWV and 100\% increase of SWS during onset of summer monsoon. The active periods are associated with TWV of $\sim 55-60 \mathrm{~mm}$. The severe deficit in July rainfall during 2002 may be linked to the reduced amount of TWV availability $(\sim 40 \mathrm{~mm})$ over EAS. The lack of moisture may have reduced the convection over the eastern Arabian Sea and thereby reducing the moisture convergence and hence weakening of the Arabian Sea branch of monsoon.

Wavelet analysis of TWV and SWS over EAS shows the time evolution of the dominant modes of quasi-biweekly 10-20 days and 30-60 days oscillation with $90 \%$ confidence level. These modes affect 

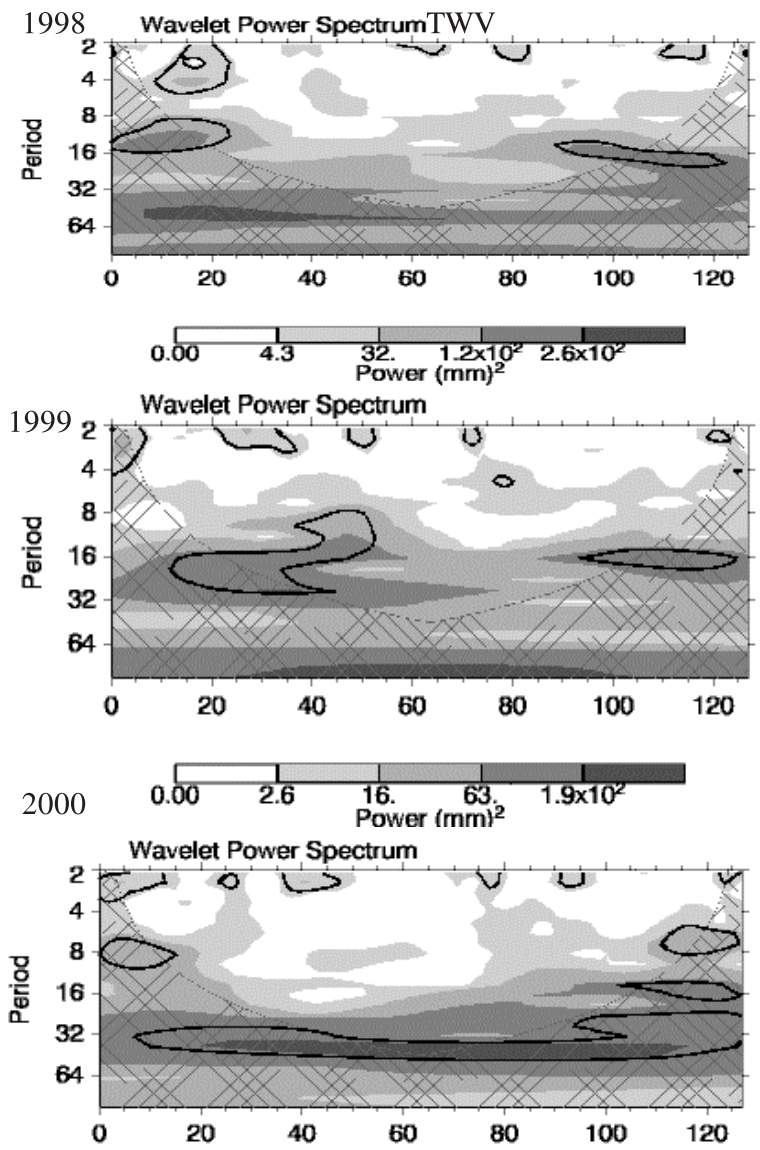

(a)

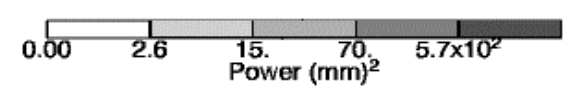

Figure 10. Wavelet power spectra for (a) TWV $\left(\mathrm{mm}^{2}\right)$ and (b) SWS (m/s) for 1998-2000.

the daily summer monsoon rainfall over west coast of India. It is important to note that the timing of the intensification of positive phase of 10-20 days and 30-60 days mode in TWV and SWS are related to the active spells of the daily summer monsoon rainfall over the west coast of India. Active and break phases of monsoon are clearly correlated with positive and negative phases of these oscillations. The west coast of India rainfall does not depend upon the amplitude of the 30-60-day and 10-20-day oscillations. It strongly depends upon the phase of the 30-60-day periodicity oscillations and also the presence of low periodicity waves. Highly active periods correspond to the simultaneous presence of positive phases of 30-60 and 10-20day periodicity oscillations.

\section{Acknowledgements}

Authors are grateful for the discussions with Dr. P S Desai, Dr. V K Agarwal, Dr. V Sathyamoorthy and Dr. P C Joshi. Authors
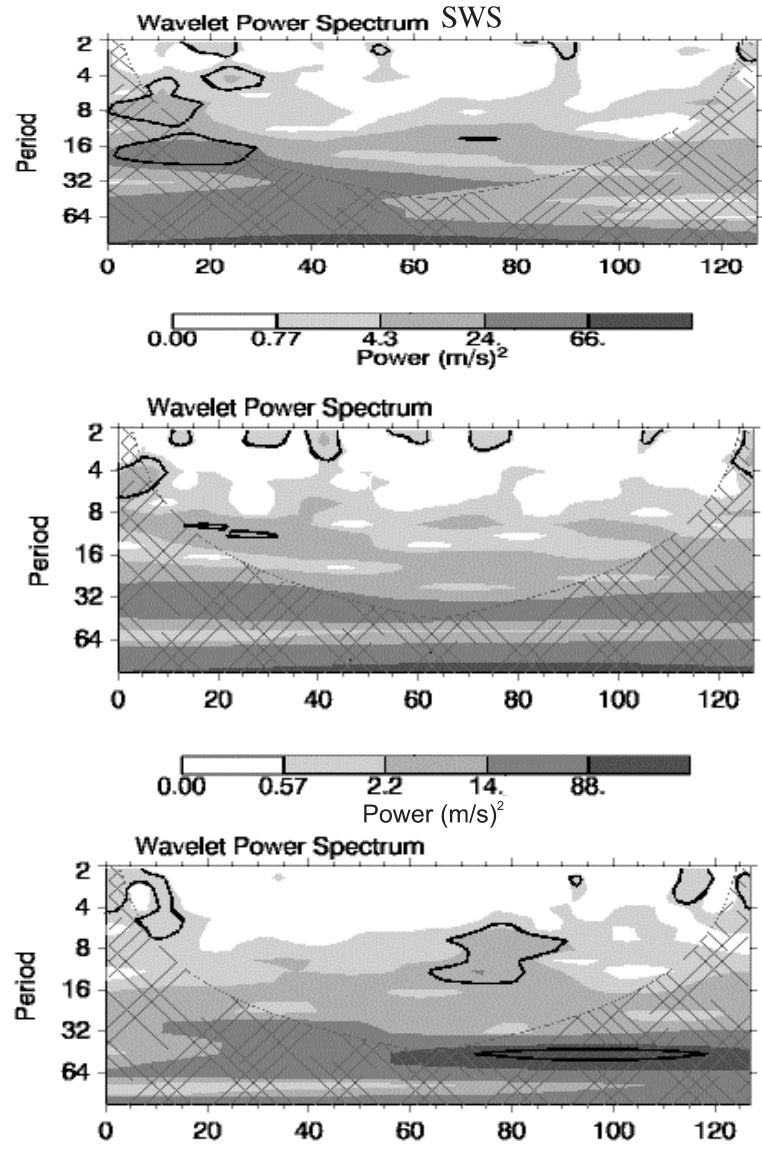

(b)

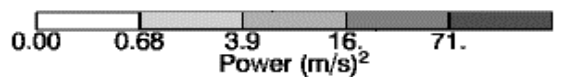

are thankful to Mr. Vihang Bhatt for scientific discussions and the help in computations. NASA/GSFC are also thankfully acknowledged for providing TMI data in website. One of the authors SHR acknowledges the research fellowship granted under ISRO-Geosphere Biosphere Programme. The online wavelet programs and software from URL: paos.colorado.edu/research/wavelet is very much acknowledged.

\section{References}

Ferranti L, Slingo J M, Palmer T N and Hoskins B J 1997 Relations between intrannual and intraseasonal monsoon variability as diagnosed from AMIP integration; Quart. J. Roy. Meteor. Soc. 123 1323-1357.

Francis P A and Sulochana Gadgil 2002 Intense rainfall events over the west coast of India; CAOS REPORT 2002 AS 1.

Goswami B N, Sengupta D and Suresh Kumar G 1998 Intraseasonal oscillations and interannual variability of surface winds over the Indian monsoon region; Proc. Indian Acad. Sci. (Earth Planet. Sci.) 107 45-64.

Goswami B N and Ajaya Mohan R S 2001 Intraseasonal oscillations and interannual variability of the Indian summer monsoon; J. Climate 14 1180-1198. 
Joseph P V, Simon A, Nair G V and Thomas A 2004 Intraseasonal Oscillation (ISO) of south Kerala rainfall during the summer monsoons of 1901-1995; Proc. Indian Acad. Sci. 113(2) 139-150.

Krishnamurti T N, Oosterhof D K and Mehta V K 1988 AirSea interaction on the time scale of 30-50 days; J. Atmos. Sci. 45(8) 1304-1322.

Krishnamurti T N and Andrunay P 1980 The 10-20 day westward propagatibg mode and 'breaks in the monsoons'; Tellus 32 15-26.

Krishnamurti T N and Bhalme H N 1976 Oscillations of a monsoon system. Part I. Observational aspects; J. Atmos. Sci. 33 1937-1954.

Kriplani R H, Kulkarni A, Sabade S S, Revadekar J V, Patwardhan S K and Kulkarni J R 2004 Intraseasonal oscillations during monsoon 2002 and 2003; Curr. Sci. 87(3) 325-331.

Ramamurthy R 1969 Monsoons of India: Some aspects of the break in the southwest monsoon during July-August. Forcasting manual. Part IV, No. 18.3, India Meteor. Dept., Pune, India.

Sajith V, Santosh K R and Ram Mohan H S 2003 Intraseasonal oscillation of total precipitable water over North Indian Ocean and its application in the diagnostic study of costal rainfall; Geophys. Res. Lett. 30(20) 2054.

Simon B, Rahman S H and Sathiyamoorthy 2003 Intraseasonal Oscillations over Tropical Indian Ocean in Relation to Monsoon Onset and Rainfall Events over the Peninsular India; Mausam 54 189-196.

Sikka D R and Gadgil S 1980 On maximum cloud zone and ITCZ over Indian longitude during the southwest monsoon; Mon. Wea. Rev. 108 1840-1853.

Sengupta D, Goswami B N and Senan R 2001 Coherent Intraseasonal Oscillations of Ocean and Atmosphere during the Asian Summer monsoon; Geophys. Res. Lett. 28(21) 4127-4130

Singh S V, Kriplani R H and Sikka D R 1992 Interannual variability of the Madden-Julian oscillations in Indian summer monsoon rainfall; J. Climate 5 973-978.

Torrence C and Compo G P 1998 A Practical Guide top Wavelet Analysis; Bull. Amer. Meteor. Soc. $\mathbf{7 9}$ $61-78$.

Weng H and Lau K M 1994 Wavelet, Period Doubling, and Time-Frequency Localization with Application to Organization of Convection over Tropical Western Pacific; J. Atmos. Sci. $512523-2541$.

Webster P J, Magana V O, Palmer T N, Shukla J, Tomas R A, Yanai M and Yasunari T 1998 Processes, predictability and prospects for prediction; J. Geophys. Res. 103 (C7) 14,451-14,510.

Yasunari T 1980 A quasi stationary appearance of 30-40 day period in cloudiness fluctuations during the summer monsoon over India; J. Meteor. Soc. Japan $\mathbf{5 8}$ 225-229. 